\title{
GMR
}

\section{SNPs in the 5'-regulatory region of the tyrosinase gene do not affect plumage color in ducks (Anas platyrhynchos)}

\author{
N.N. Zhang, J.W. Hu, H.H. Liu, H.Y. Xu, H. He and L. Li \\ Farm Animal Genetic Resources Exploration and Innovation Key Laboratory of \\ Sichuan Province, Sichuan Agricultural University, Ya'an, Sichuan, China \\ Corresponding author: L. Li \\ E-mail: liliang@sicau.edu.cn
}

Genet. Mol. Res. 14 (4): 18623-18628 (2015)

Received March 25, 2015

Accepted June 12, 2015

Published December 28, 2015

DOI http://dx.doi.org/10.4238/2015.December.28.11

\begin{abstract}
Tyrosinase, encoded by the TYR gene, is the rate-limiting enzyme in the production of melanin pigment. In this study, plumage color separation was observed in Cherry Valley duck line D and F1 and F2 hybrid generations of Liancheng white ducks. Gene sequencing and bioinformatic analysis were applied to the 5'-regulatory region of $T Y R$, to explore the connection between $T Y R$ sequence variation and duck plumage color. Four SNPs were found in the 5'-regulatory region. The SNPs were in tight linkage and formed three haplotypes. However, the genotype distribution in groups with different plumage color was not significantly different, and there were no changes in the transcription factor binding sites between the different genotypes. In conclusion, these SNP variations may not cause the differences in feather color observed in this test group.
\end{abstract}

Key words: Duck; Tyrosinase gene; Promoter; SNP; Plumage color 


\section{INTRODUCTION}

Animal coat and plumage color is determined mainly by the content of eumelanin and pheomelanin in the skin. Eumelanin biosynthesis and distribution is regulated by a large number of genes. Mutations in these genes may affect color variation, but interactions between genes can also control plumage color. Tyrosinase, encoded by $T Y R$, is the rate-limiting enzyme in the production of melanin pigment (Sanchez-Ferrer et al., 1995). It is a copper-containing enzyme that catalyzes the first two steps in the melanin biosynthesis pathway, converting tyrosine to L-dihydroxy-phenylalanine (DOPA), which is subsequently converted to DOPA quinone (Cooksey et al., 1997). The enzyme determines which type of melanin (eumelanin or pheomelanin) is synthesized (Kwon et al., 1987; Ito et al., 2000).

Close to 200 mutations have been found in TYR (Stenson et al., 2009). Non-synonymous SNPs occurring in coding regions result in single amino acid polymorphisms, which may affect protein function and lead to pathogenic phenotypes (Capriotti et al., 2011). Previous studies have shown that TYR mutations are associated with albinism in many vertebrates, including humans (Oetting, 2000), rats (Blaszczyk et al., 2005), cattle (Schmutz et al., 2004), cats (Imes et al., 2006), chickens (Liu et al., 2010), and geese (Wang et al., 2014). Peking ducks have a mutation in exon 1 of $T Y R$, but whether this affects the color traits of duck feathers has not been determined. To investigate whether variations in the 5'-regulatory region of TYR are related to the plumage color of ducks, and to determine possible mechanisms of variations in this region, Cherry Valley line D (white) and Liancheng white (white) F1 and F2 hybrid generation ducks were studied.

\section{MATERIAL AND METHODS}

\section{Animals}

Cherry Valley line D and Liancheng white hybrid F1 and F2 generation ducks were obtained from the Sichuan Agricultural University Waterfowl Breeding Experimental Farm. Ducks were raised in a poultry house by specialized staff and the different lines were under the same nutrition and management conditions. The F1 generation animals all had gray plumage, while the plumage colors of the F2 generation were black, white, gray, and spotted (black and white). Venous blood samples were collected from 109 ducks displaying the four different plumage colors, including eight gray F1 and 16 black, 35 white, 24 gray, and 26 spotted F2 ducks. Genomic DNA was prepared from blood using a standard phenol/chloroform method (Wang et al., 2014) and stored at $-20^{\circ} \mathrm{C}$ for sequencing of the TYR promoter.

\section{Sequencing and genotyping of TYR}

Primers were designed based on the genome sequence of TYR from Peking duck (NCBI Reference Sequence: NW_004678775.1) using the Primer 5.0 (PREMIER Biosoft International, Canada) and the Oligo 6.0 (Molecular Biology Insights Inc., Cascade, CO, USA) softwares. The primers were as follows: 5'-AACAATGACAGCCGAAG-3' (forward) and 5'-CTGCTACACTACACCCTACAAT-3' (reverse). Polymerase chain reactions (PCRs) were performed using 1X Taq Master Mix (Takara Biotech Co., Dalian, China); 50 ng genomic DNA; and $0.2 \mu \mathrm{M}$ of each primer, in a volume of $25 \mu \mathrm{L}$. Thermal cycling parameters were as follows: $95^{\circ} \mathrm{C}$ for $5 \mathrm{~min} ; 36$ cycles of $95^{\circ} \mathrm{C}$ for $45 \mathrm{~s}, 53.4^{\circ} \mathrm{C}$ for $45 \mathrm{~s}$, and $72^{\circ} \mathrm{C}$ for $1 \mathrm{~min}$; and $72^{\circ} \mathrm{C}$ for $10 \mathrm{~min}$. Completed reactions were stored at $4^{\circ} \mathrm{C}$ until directly sequencing using an ABI Prism 3700 DNA sequencer (Shanghai Biotech Co., Shanghai, China). 


\section{Data analysis}

Sequences were spliced and aligned using DNAMAN 6.0.3.99 (Lynnon Biosoft, USA). TYR haplotypes were deduced from the sequencing traces. Allele and genotype frequency determinations in the F2 generation, along with Chi-square tests for Hardy-Weinberg equilibrium, were performed using the PopGen32 software (Version 1.31). Potential associations between TYR alleles and plumage color were evaluated with a Chi-square test for independence, using the TBM SPSS 19 software (International Business Machines Corp, USA). CpG islands (cytosine-guanine) were predicted using the CpGPlot software (http://www.bioon.com.cn/doc/showarticle. asp?newsid=1115). Promoter regions, TATA boxes, and transcription start sites were predicted by Neural Network Promoter Prediction (http://www.fruitfly.org/seq_tools/promoter.html), and the Web Promoter Scan Service (http://www-bimas.cit.nih.gov/molbio/proscan/). The effects of TYR mutations on transcription factor binding sites were predicted using Signal Scan (http://www-bimas.cit.nih.gov/molbio/signal/).

\section{RESULTS}

We amplified $967 \mathrm{bp}$ fragments (1094 to $128 \mathrm{bp}$ ) of the 5'-regulatory region of TYR. DNA sequencing detected four SNPs (570T>C, 495C>A, 366_365TG>CA, and 293A>C), all of which were found in F1 ducks, and in F2 ducks of each plumage color. There was evidence of tight linkage between the four mutations, with only two combinations of variations, defined as A (T-C-TG-A) and B (C-A$\mathrm{CA}-\mathrm{C}$ ). Three haplotypes (AA, AB, and BB) were observed in the F1 and F2 generations (Figure 1).

The F2 generation group was in Hardy-Weinberg equilibrium for the variant sites (Chisquare analysis; $P=0.189$ ). Allele and genotype frequency distribution in the $F 1$ and $F 2$ generations are shown in Table 1. Chi-square tests showed that the distribution of genotypes in F2 ducks with different plumage colors was not significantly different $\left[X^{2}(6)=3.15 ; P=0.790\right]$.

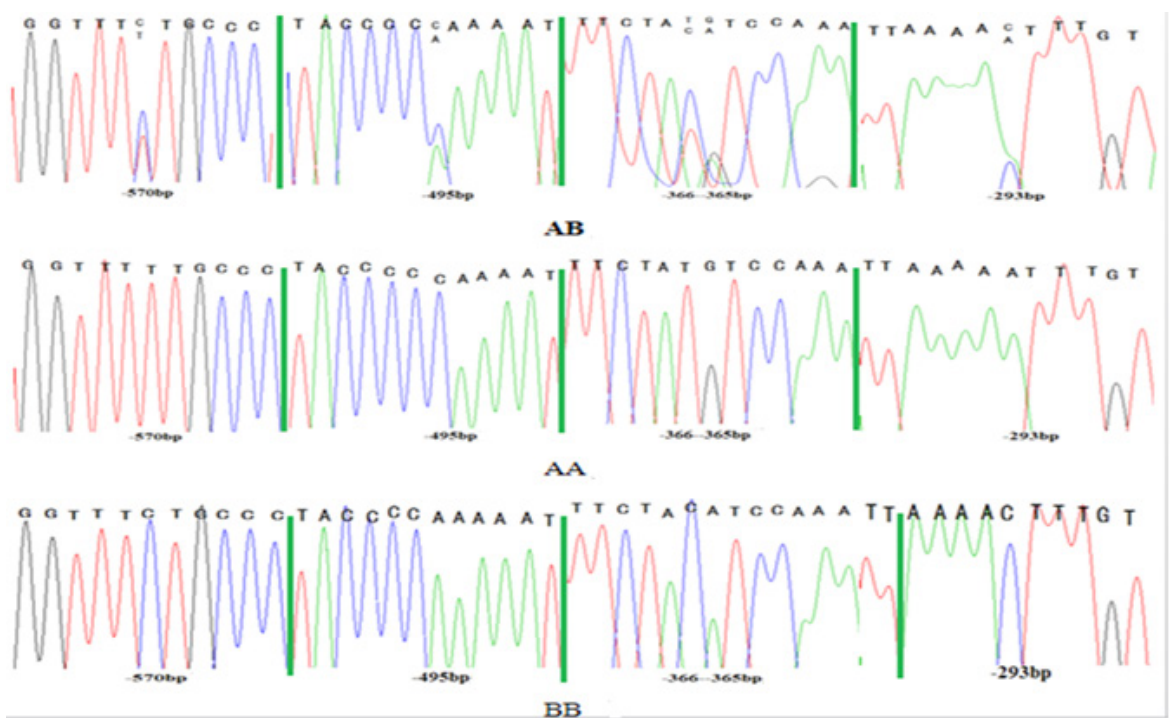

Figure 1. Sequencing results of four SNP loci from different genotypes. There were three haplotypes in the F1 and F2 generations. The four SNPs were in tight linkage, and with only two combinations of variations, defined as A (T-C-TG-A) and B (C-A-CA-C). 


\begin{tabular}{|c|c|c|c|c|c|c|c|c|}
\hline \multirow[t]{2}{*}{ Generation } & \multirow[t]{2}{*}{ Colour } & \multicolumn{3}{|c|}{ Genotype frequency } & \multirow[t]{2}{*}{ Total } & \multicolumn{2}{|c|}{ Allele frequency } & \multirow[t]{2}{*}{ Total } \\
\hline & & AA & $A B$ & BB & & A & B & \\
\hline $\mathrm{F} 1$ & Gray & $12.5 \%(1)$ & $75.0 \%(6)$ & $12.5 \%(1)$ & $100 \%(8)$ & $50.00 \%$ & $50.00 \%$ & $100 \%$ \\
\hline \multirow[t]{4}{*}{$\mathrm{F} 2$} & Black & $31.3 \%(5)$ & $50.0 \%(8)$ & $18.8 \%(3)$ & $100 \%(16)$ & $53.33 \%$ & $46.67 \%$ & $100 \%$ \\
\hline & White & $14.3 \%(5)$ & $48.6 \%(17)$ & $37.1 \%(13)$ & $100 \%(35)$ & $36.76 \%$ & $63.24 \%$ & $100 \%$ \\
\hline & Gray & $20.8 \%(5)$ & $45.8 \%(11)$ & $33.3 \%(8)$ & $100 \%(24)$ & $41.30 \%$ & $58.70 \%$ & $100 \%$ \\
\hline & Spotted & $19.2 \%(5)$ & $42.3 \%(11)$ & $38.5 \%(10)$ & $100 \%(26)$ & $38.00 \%$ & $62.00 \%$ & $100 \%$ \\
\hline
\end{tabular}

The GC content of the amplified TYR regulatory region was 35\%, and no CpG island was predicted by CpGPlot. Using the Neural Network system, promoters were predicted at 791 to 741 and 200 to $150 \mathrm{bp}$ on the forward strand, and at 411 to 472,467 to 517 , and 635 to $685 \mathrm{bp}$ on the reverse strand (Table 2). The Web Promoter Scan Service predicted a promoter region on the reverse strand at 207 to 557 , a TATA box at 432, and a transcription start site at 464 bp. Transcription factor binding sites predicted by Signal Scan did not differ for any of the described SNPs.

\begin{tabular}{|c|c|c|c|}
\hline \multicolumn{3}{|c|}{ Promoter predictions for sequence } & \multirow[t]{2}{*}{ Promoter sequence } \\
\hline$\underline{\text { Start }}$ & End & Score & \\
\hline$-791 \mathrm{bp}$ & $-741 b p$ & 0.68 & AAATTGCCTGTATTCTCCAAAAAACTGCAGAGATTCGGGTGCAGATTTGA \\
\hline$-200 \mathrm{bp}$ & $-150 b p$ & 0.72 & GTGTATTCTGTGTGTTAATGTGCCCAGGGTAGGAATGGGGAAGGACATTG \\
\hline \multicolumn{4}{|c|}{ Promoter predictions for the reverse strand of sequence } \\
\hline$-411 b p$ & $-472 b p$ & 0.98 & AATGATTGTTTAAAAAAACTCAGAAGAATCTGACCAATTAAATAAGCACA \\
\hline$-467 \mathrm{bp}$ & $-517 \mathrm{bp}$ & 0.67 & GCACAGTGAATATAAACATGAGAAAAATATTTTTGGGGTAGACTACATTT \\
\hline$-635 b p$ & -685 bp & 0.69 & AGGCTAGCATATAACAAAGTGTCTTCACAAGAGAGCTGACAAACTTTTCA \\
\hline
\end{tabular}

\section{DISCUSSION}

TYR is an important candidate for the regulation of melanin biosynthesis. TYR mutations have been confirmed in mammals including humans, rats, mice, rabbits, and cattle, and are associated with albinism (Yokoyama et al., 1990, Aigner et al., 2000, Schmutz et al., 2004, Blaszczyk et al., 2005, Imes et al., 2006). Balu and Rituraj (2013) proposed that the structural and functional behavior of tyrosinase, upon mutation, could lead to skin albinism. Using an albino hybrid strain, researchers produced transgenic rabbits expressing the murine tyrosinase gene, and tyrosinasetransgenic rabbits showed a greater variety in hue, intensity and extent of coat pigmentation, which is caused by the diversity in the loci affecting the melanization (Aigner et al., 1996). The expression level of $T Y R$ in dark-iris rabbits was significantly higher than that in non-pigmented rabbits, and the study concluded that the $1118 \mathrm{C}>\mathrm{A}$ substitution affected tyrosinase function, and that the level of $T Y R$ expression is related to iris color in rabbits. Studies in humans have found that tyrosinase activity in the skin is higher for black people, compared to white people (Pomerantz and Ances, 1975, Iwata et al., 1990). A study in Suffolk sheep demonstrated that albinism displays autosomal recessive inheritance. Histochemical tests of sheep revealed defective melanin synthesis at the tyrosine to DOPA conversion step, but not the subsequent reactions that lead to melanin (Rowett et al.,1993). 
Mochii et al. (1992) cloned and analyzed chicken TYR, and observed a significant difference in the expression level of TYR mRNA in feather pulp between black and grayish-white Bian chickens. Real-time quantitative PCR experiments showed that TYR expression levels influence feather color of both half- and full-Muscovy ducks (Zheng et al., 2013). Wang et al. (2014) detected three SNPs in a cloned 588 bp fragment of the TYR exon 1, and suggested an association between TYR polymorphisms and plumage color in domestic geese.

In mammals, TYR structure is regulated by the 5 '-regulatory region, and shows different pigment deposition phenotypes (Methot et al., 1995). Single-strand conformational polymorphism analysis was applied to the upstream regulatory region of chicken TYR, from 641 to $2125 \mathrm{bp}$. Three SNPs were found in this region and results indicated that these mutations were significantly associated with shank and body skin color in chickens (Chen et al., 2005). Correlations between SNPs and pigment traits in parental and F2 generations of China Agricultural University chicken populations were analyzed by Chi-square test; these results also indicated that the variants were significantly associated with shank and skin color. In our study, four SNPs that were in tight linkage were found in the 5'-regulatory region of TYR from 1094 to $128 \mathrm{bp}$. These SNPs formed three haplotypes. However, there was no significant difference in genotype distribution between F2 ducks with different plumage colors. Bioinformatic analysis of these sequences showed that, although promoter regions and a TATA box may exist in this segment, transcription factor binding sites did not differ between the genotypes. We speculate that variations in this region do not cause changes in expression of $T Y R$, and are thus not the cause of the differences in feather color seen in this study group. Melanin synthesis is an extremely complicated process, and the molecular mechanisms of plumage color determinants in Cherry Valley and Liancheng white hybrid ducks remain to be determined.

\section{Conflicts of interest}

The authors declare no conflict of interest.

\section{ACKNOWLEDGMENTS}

Research supported by the Science and Technology Support Plan (\#2011NZ0099-8, \#2014NZ0030) and the Educational Innovation Team Project (\#13TD0034) of Sichuan.

\section{REFERENCES}

Aigner B, Besenfelder U, Seregi J and Frenyo LV (1996). Expression of the murine wild-type tyrosinase gene in transgenic rabbits. Transgenic Res. 5: 405- 411.

Aigner B, Besenfelder U, Mueller M and Brem G (2000). Tyrosinase gene variants in different rabbit strains. Mamm. Genome 11: 700-702.

Balu K and Rituraj P (2013). Mutational analysis of TYR gene and its structural consequences in OCA1A. Gene 513: 184-195.

Blaszczyk WM, Arning L, Hoffmann KP and Epplen T (2005). A tyrosinase missense mutation causes albinism in the Wistar rat. Pigm. Cell Res. 18: 144-145.

Capriotti E and Altman RB (2011). Improving the prediction of disease-related variants using protein three-dimensional structure. BMC Bioinformatics 12 (Suppl 4): S3.

Chen ZQ, Deng XM, Zhou J, Li N, et al. (2005). Analysis of the single-strand conformation polymorphisms of the upstream 5'-regulating region of chicken tyrosinase (TYR) gene. J. Agric. Biotechnol. 13: 191-194.

Cooksey CJ, Garratt PJ, Land EJ, Pavel S, et al. (1997). Evidence of the indirect formation of the catecholic intermediate 
substrate responsible for the autoactivation kinetics of tyrosinase. J. Biol. Chem. 272: 26226-26235.

Imes DL, Geary LA, Grahn RA and Lyons LA (2006). Albinism in the domestic cat (Felis catus) is associated with a tyrosinase (TYR) mutation. Anim Genet. 37: 175-178

Ito S, Wakamatsu K and Ozeki $\mathrm{H}$ (2000). Chemical analysis of melanins and its application to the study of the regulation of melanogenesis. Pigm. Cell Res. 13 (Suppl 8): 103-109.

Iwata M, Corn T, Iwata S, Everett MA, et al. (1990). The relationship between tyrosinase activity and skin color in human foreskins. J. Invest. Dermatol. 95: 9-15.

Kwon BS, Haq AK, Pomerantz SH and Halaban R (1987). Isolation and sequence of a cDNA clone for human tyrosinase that maps at the mouse c-albino locus. PNAS 84: 7473-7477.

Liu W, Chen SR, Zheng JX, Qu LJ, et al. (2010). Developmental phenotypic-genotypic associations of tyrosinase and melanocortin 1 receptor genes with changing profiles in chicken plumage pigmentation. Poult. Sci. 89: 1110-1114.

Methot D, Reudelhuber TL and Silversides DW (1995). Evaluation of tyrosinase minigene co-injection as a marker for genetic manipulations in transgenic mice. Nucleic Acids Res. 23: 4551-4556.

Mochii M, lio A, Yamamoto H, Takeuchi T, et al. (1992). Isolation and characterization of a chicken tyrosinase cDNA. Pigm. Cell Res. 5: 162-167.

Oetting WS (2000). The tyrosinase gene and oculocutaneous albinism type 1 (OCA1): a model for understanding the molecular biology of melanin formation. Pigm. Cell Res. 13: 320-325.

Pomerantz SH and Ances IG (1975). Tyrosinase activity in human skin. Influence of race and age in newborns. J. Clin. Invest. 55: 1127-1131.

Rowett MA and Fleet MR (1993). Albinism in a Suffolk sheep. J. Hered. 84: 67-69.

Sanchez-Ferrer A, Rodriguez-Lopez JN, Garcia-Canovas F and Garcia-Carmona F (1995). Tyrosinase: a comprehensive review of its mechanism. Biochim. Biophys. Acta 1247: 1-11.

Schmutz SM, Berryere TG, Ciobanu DC, Mileham AJ, et al. (2004). A form of albinism in cattle is caused by a tyrosinase frameshift mutation. Mamm. Genome 15: 62-67.

Stenson PD, Mort M, Ball EV, Howells K, et al. (2009). The Human Gene Mutation Database: 2008 update. Genome Med. 1: 13.

Wang Y, Li SM, Huang J, Chen SY, et al. (2014). Mutations of TYR and MITF genes are associated with plumage colour phenotypes in geese. Asian-Australas J. Anim. Sci. 27: 778-783.

Yokoyama TD, Silversides W, Waymire KG, Kwon BS, et al. (1990). Conserved cysteine to serine mutation in tyrosinase is responsible for the classical albino mutation in laboratory mice. Nucleic Acids Res. 18: 7293-7298.

Zheng NZ, Xin QW, Miao ZW, Zhu ZM, et al. (2013). Differential expressions of melanin genes in the mule and muscovy duck with different plumage colors. Fujian J. Agric. Sci. 28: 427-431. 